CHAPTER 5

\title{
The Vital Need for Ontological, Epistemological and Methodological Diversity in Applied Linguistics
}

\author{
Jean-Marc Dewaele, Birkbeck, University of London
}

\begin{abstract}
Introduction
Applied linguistics has been a battleground for researchers with different theoretical bases, ontological positions, epistemological priorities and methodological preferences. In the present contribution I will focus on the criticism that was levelled at quantitative research into individual differences (IDs) in applied linguistics, and more specifically the affective SLA research developed by Gardner and MacIntyre (1993) by poststructuralist researchers and by researchers inspired by dynamic system theory (DST). Despite the very distinct theoretical backgrounds of poststructuralist and DST researchers, the criticisms were actually quite similar in nature and reflected unhappiness with the dominant ontological, epistemological and methodological choices in the field. Indeed, early research in applied linguistics was dominated by an etic perspective, relying mainly on quantitative data and statistical analysis, while at the start of the 21 st century a much larger proportion of researchers started embracing the emic perspective, relying on qualitative data in order to hear
\end{abstract}

How to cite this book chapter:

Dewaele, J-M. 2019. The Vital Need for Ontological, Epistemological and Methodological Diversity in Applied Linguistics. In: Wright, C., Harvey, L. and Simpson, J. (eds.) Voices and Practices in Applied Linguistics: Diversifying a Discipline, pp. 71-88. York: White Rose University Press. DOI: https://doi.org/10.22599/BAAL1.e. Licence: CC BY-NC 4.0 
participants' voices (Pike 1954; Firth \& Wagner 2007). Some central figures in the field, like Dörnyei, reflect this shift in their own work. In his Research Methods in Applied Linguistics (2007) Dörnyei - well known for his quantitative leanings - stated:

although I genuinely appreciate qualitatively oriented colleagues' skills in teasing meaningful patterns out of masses of rather fluid and messy data, my attraction to well-structured systems, clear-cut boundaries, standardized procedures, and statistical analyses make me more naturally a quantitative researcher.

(Dörnyei 2007: 174)

A mere five years later, Dörnyei rejected statistical analysis of groups: 'aggregated scores from a sample are often meaningless when one tries to understand the intricate dynamics of a complex system' (Dörnyei 2012: 4).

I propose to discuss the criticisms and offer a defence of quantitative 'affective' research, including the use of group averages, in order to avoid it being kicked aside in mainstream applied linguistic research. Quantitative affective research in SLA, and in applied linguistics in general, offers a fertile ground for crucial interdisciplinary collaboration between applied linguists, psychologists and education specialists from different backgrounds. Such collaborations need to continue, and to grow further, not just because they can lead to much needed methodological and epistemological diversity (Prior 2019) and triangulation of elusive phenomena and hence to theoretical innovation but also because the pedagogical implications of this research can serve the foreign language teaching community, and by extension foreign language learners in general.

I will start with defining some basic concepts before delving into the objections from poststructuralist researchers. The focus will be on Pavlenko's (2002, 2013) insightful criticisms of quantitative affective SLA. After that, I will look into DST-based researchers' more recent disengagement from the quantitative affective SLA. The guiding questions are as follows: should quantitative affective SLA researchers simply give up and cancel their SPSS licences? Is there a way to continue in the quantitative tradition with a stronger awareness of its limitations? What would be the consequences of abandoning quantitative methods to study affective SLA?

\section{Some epistemological issues}

The opposition between 'emic' and 'etic' was introduced by cultural anthropologist Pike (1954) in his pursuit of tools that could describe all human social behaviour. Pike's main argument was that interpretive (etic) frameworks by outsiders differ from culturally specific (emic) frameworks used by insiders of a culture for interpreting and assigning meaning to their experiences. Etic/ 
quantitative approaches are rooted in the positivistic paradigm, where researchers are assumed to be impartial in their investigations of cause-effect relationships between the variables in a world of real objects (Farhady 2013: 1). Emic analyses, on the other hand, are based on participants' un/conscious perspectives and interpretations of behaviour, events and situations in their own words (Pike 1954). In other words, participants' voices are heard. This emic/qualitative approach is 'comparatively heterogeneous in its aims and methodologies,' covering case study research, conversation analysis and (critical) ethnography (Markee 2013: 1). There is also much more variation in ontological and epistemological assumptions of researchers using an emic/qualitative approach (p. 3).

One example of emic research is the narrative approach, which considers human beings as creators and interpreters of meaning (Pavlenko 2008; Pomerantz 2013). Narratives are seen as a shared sense-making process where researchers 'seek an emic or insider's account of the cognitive, social, and emotional dimensions of SLA, one that is not necessarily open to etic or outside observation' (Pomerantz 2013: 1). The push for emic perspectives did not imply a complete rejection of etic approaches but rather an epistemological rebalancing of the field. Pavlenko (2008), for example, pleaded for triangulation, warning researchers that 'participants' stories are interpretations, and not representations, of reality, and are best used in conjunction with other means of data collection' (2008: 324).

Traditional affective research in SLA was very much steeped in the etic/ quantitative perspective: opinions and attitudes of participants were collected through research instruments designed and formulated by the researchers. Dörnyei and Ryan (2015) explained that pioneers like Gardner were statisticians, which explained the relatively narrow quantitative approach (2015: 91). Schrauf (2016) argues that it is wrong to label the quantitative approach as exclusively etic. Data collection through surveys and semi-structured interviews 'are both thoroughly discursive, interactional events in which meaning is collaboratively produced by both respondent and interviewer' (2016: xi). Both qualitative and quantitative data undergo extensive transformation prior to analysis. Schrauf explains that qualitative data require technically precise and fine-grained transcription. In quantitative surveys, 'data is ultimately transformed into participants' belief statements (items) with linguistic "stances" (response options) reported on a standard spreadsheet. I argue that linguistic stance is at the heart of survey response' (2016: xi). Schrauf's argument is a valid one, in the sense that the urge to distinguish etic/quantitative from emic/ qualitative approaches might create an artificial view of incommensurability of findings generated by quantitative methods on the one hand and qualitative research methods on the other. Similar views have been expressed by LarsenFreeman and Long (1991), who have argued that quantitative and qualitative approaches are not mutually exclusive as both entail some degree of categorisation and quantification of data. It is thus crucial to avoid gross simplifications. Similarly, Dörnyei argued: 
although there is no shortage of convincing intellectual arguments to justify paradigm incompatibility, most researchers have actually stopped short of claiming the inevitability of this conflict and, particularly in the last decade, scholars have started to look for some sort of an interface between the two research traditions.

(Dörnyei 2007: 29)

\section{The poststructuralist challenge}

Pavlenko (2013), in an essay on the affective turn in second language acquisition (SLA), celebrates the recent interest in emotion in SLA: 'In the past decade ... we have witnessed an affective turn, which has dramatically transformed and expanded the scope of research on the role of affect in SLA' (2013: 5). She starts a section with the provocative title Affective Factors and Why They Don't Work. Pointing to three major SLA textbooks, she notes that their authors consider studies focused on the link between SLA and language affect, loosely defined as feelings or emotional reactions about the language, its users and its culture and lumped together with other individual differences (IDs), such as 'anxiety, motivation, personality characteristics and willingness to communicate' (2013: 6), with the aim of establishing 'whether there is a causal relationship between "affective actors" and L2 acquisition' and whether 'affective variables can explain individual variation in SLA and can be predictors of success' (2013: 7). Pavlenko feels that the textbook authors failed to highlight the 'atheoretical and reductionist nature of the paradigm,' the fact that 'the study of affect has moved beyond "affective" factors' (ibid.), that no attention was paid to other emotions but anxiety and 'the search for linear cause-and-effect relationship between affective factors and achievement in the absence of any psycholinguistic theory of how such influence may take place' (ibid.). The search for predictors of FL achievement is doomed to failure, according to Pavlenko, because 'anxiety, attitudes and motivation are dynamic and social phenomena and the relationship and the relationship between these phenomena and levels of achievement is reciprocal rather than unidirectional' (2013: 8). Moreover, affective factors cannot be treated separately from the linguistic and social contexts (ibid.). She illustrates her theoretical points with her own polyglot history, which started with Polish at the age of eight in Kiev with a tutor called Pani Zhanna. The memories are linked to books, to libraries, which are a 'magical world' containing hidden treasures, including books of Polish poets:

It was not love for a speaker of the language (those were far and few in between in Soviet Kiev), nor a desire for an alternative identity in Polish (where would I perform such an identity and for whom?). It was 
pure and unadulterated love for the music of a foreign language, which I never experienced again.

(Pavlenko 2013: 5)

In her conclusion, Pavlenko argues that 'to understand L2 learners' crossings and transitions between different affective worlds, the emerging field of L2 learning and affect will require a genuine dialogue and collaboration between scholars from different disciplines' (2013: 24).

Pavlenko's criticism of the lumping together of affective variables and the other IDs by textbook authors is directed at the authors rather than the researchers who investigated IDs. However, the claim that the paradigm itself is atheoretical and reductionist has a grain of truth in it. I have compared the investigation into the causes for IDs in SLA to the search for the Holy Grail in which researchers resemble 'Arthur's knights, stumbling through the night, guided by a stubborn belief that something must be there, glimpsing tantalizing flashes of light from a distance, only to discover that their discoveries looked rather pale in the daylight' (Dewaele 2009a: 625). The disappointing findings are linked to the interdisciplinary nature of this research area: it requires considerable theoretical knowledge and methodological skill in personality psychology and social psychology, as well as various subfields of applied linguistics, educational psychology, sociolinguistics and psycholinguistics, to carry out a study that is theoretically and methodologically consistent. It is inevitable that researchers stick to the paradigm that they know best, which implies a theoretical and methodological reduction in scope. The variety of theories on IDs in different paradigms means that interdisciplinary researchers struggle with an overload of potentially incompatible theories rather than an absence of them (Dewaele 2012).

Pavlenko's complaint that there is an absence of solid psycholinguistic theory in research on affective factors is a valid one. This is a gap that is only just attracting researchers' attention (cp. Saito, Dewaele \& Hanzawa 2017) and requires further research. Her observation that too much attention was given to anxiety was correct and this has been rectified in the last five years with a more holistic take on positive as well as negative learner emotions (Dewaele \& MacIntyre 2014; MacIntyre, Gregersen \& Mercer 2016; see Dewaele 2018a for a recent overview).

Pavlenko's conclusion hits the nail on the head: to understand the complexity, richness and the dynamic nature of L2 learners' affective and linguistic crossings and transitions, we need dialogue between researchers with different ontological, epistemological and methodological backgrounds to make progress in this highly interdisciplinary area of research.

Pavlenko and Lantolf (2001) and Pavlenko (2002) had already listed their objections to purely etic, cognitive and sociopsychological approaches in SLA. Pavlenko and Lantolf (2001) argued that SLA is more than the acquisition of 
grammar, lexicon and phonology, seeing instead SLA as a struggle for participation in which learners 'have intentions, agency, affect, and above all histories, and are frequently though not always, known as people' (2001: 155). Existing quantitative sociopsychological studies that considered affect failed to impress Pavlenko. According to Pavlenko (2002), firstly, they suffered from a monolingual and monocultural bias and an outdated view about individuals moving neatly from one group to another (2002: 279). Gardner's concept of integrative motivation is therefore inherently biased, she claims, because it 'posits the necessity to abandon one's first language and culture in order to learn the L2 and acculturate to the target language group' (2002: 280). She argues in favour of a more dynamic view with simultaneous membership in different ethnic, social and cultural groups. She defends Bourdieu's view of language as symbolic capital, rejecting a 'reductionist, static and homogeneous view of culture' (2002: 280). Her second point addresses the lack of explanatory validity of quantitative sociopsychological research because constructs such as 'identity', 'in-group membership' or 'accommodation' are themselves in need of explanation (2002: 280). Her third objection is linked to the 'causal, unidirectional and stable nature attributed to such constructs as motivation, attitudes, or social distance' (2002: 280). She points out that motivation and social contexts are continuously reshaped which may lead to ebbs and flows in learners' motivation. Her fourth point concerns her perception of an artificial separation in sociopsychological approaches between social factors and the individual or psychological factors. Factors such as age, gender or ethnicity are also socially and culturally constituted which means that the understanding and implications of age, gender or ethnicity are highly variable. In other words, the 'understanding and implications of being Jewish or Arab, young or old, female or male are not the same across communities and cultures' (2002: 281). Pavlenko's fifth target for criticism is the validity of questionnaires as a research instruments because it is not clear 'what exactly was measured by the multiple questionnaires that attempted to quantify language attitudes, motivation, acculturation or language proficiency, in particular, when the latter was reduced to self-evaluation' (2002: 281).

Her sixth point concerns the Anglo-centrism of the sociopsychological paradigm, which had not prevented researchers from assuming that their findings would apply to any location. Finally, Pavlenko criticises sociopsychological researchers' view of 'the idealised and decontextualised nature attributed to language learning, which is presented as an individual endeavour, prompted by motivation and positive attitudes, and hindered by negative attitudes and perceptions' (2002: 281). Poststructuralists, on the other hand, consider complex situations in which L2 users move between different contexts or create rich, hybrid identities and where language attitudes and language learning beliefs are recast as ideologies, 'illuminating the socially constructed nature of beliefs previously seen as individual' (2002: 296). Norton Peirce (1995), for example, recasts 'motivation' as investment which is shaped by social contexts, 
including power relations of gender, race and class, which affect investments, learning trajectories and, ultimately, outcomes. Rejecting questionnaires and quasi-experimental designs, poststructuralists prefer ethnographic approaches to examine the dynamic nature of both the learner language itself and the social contexts of its learning and use (2002: 297).

In the same poststructuralist vein, Kramsch (2006) rejects

pragmatic notions like 'motivation' ... 'affect' and 'appraisal' ... economic notions like 'investment' ... or critical/political concepts like 'engagement' (2006: 209), focusing instead on 'desire' in language learning, defined as 'the never ending striving for self-fulfilment and the sense of plenitude that can be found in the act of acquiring a semiotic system and making it our own.'

(Kramsch 2006: 211)

Kramsch argues that to understand desire, researchers need to delve into language memoirs and learners' testimonies, or elicit metaphors for learning particular languages (ibid.).

In Dewaele (2009b), I considered postmodernists' objections and defended the quantitative sociopsychological approach. My main argument was that Dörnyei showed an increasing awareness of the benefits of theoretical, epistemological and methodological diversity in attitude and motivation research (Dörnyei 2005, 2007). I also defended the usefulness of questionnaires pointing out that data obtained in this way have been shown to be valuable and can come closest to catching elusive phenomena, while admitting that everything depends on the claims based on the analyses of this type of data. Dörnyei (2005, 2007) pointed out that the quantitative approach in attitude and motivation research was 'systematic, rigorous, focused, and tightly controlled, involving precise measurement and producing reliable and replicable data' (Dörnyei 2007: 34). However, Dörnyei admitted that quantitative research has limitations, namely its limited general exploratory capacity. He identified qualitative research as an avenue to explore uncharted areas and trying to understand the bigger picture: 'I have also experienced again and again how much richer data we can obtain in a well-conducted and analysed qualitative study than even in a large-scale questionnaire survey' (2007: 47). Indeed, qualitative methods are ideal to broaden the repertoire of possible interpretations and can allow researchers to get a glimpse of dynamic phenomena (Dörnyei 2007). Dörnyei (2007) and MacIntyre (2007) were aware of the downside of qualitative methodologies, namely the small sample size, the idiosyncratic focus, the difficulties of biases in reporting memories, the complexity or narrowness of theories and the labour-intensiveness of dealing with qualitative data. Both authors defended multi-method approaches in SLA, arguing that to study affective changes we need 'a combination of quantitative and qualitative approaches' (MacIntyre 2007: 573). This resonates with Ushioda (2001), who defended the 
inclusion of a qualitative perspective in motivation research to complement its long-standing quantitative tradition.

The basis of the poststructuralist claim that etic-oriented, quantitative sociopsychological researchers consider learners as mere bunches of variables stripped of intentionality and individuality (Lantolf and Pavlenko 2001) is slowly dissolving. MacIntyre (2007) focused on the concept of volition, i.e., free will, thus acknowledging that L2 learners are not predictable puppets on strings, whose actions are determined by their linguistic, social or psychological past, present and imagined future. One could argue that modern 'positivists' might not be as fanatical about quantification as some poststructuralists portray them, and that consensus is growing about the need for and value of interdisciplinary approaches with a solid theoretical basis. Similarly, postmodernists have a nuanced view on the use of quantification. Kramsch (2014), in her overview of the multidisciplinary field of applied language studies, urges applied linguists to adopt insights gained in psycholinguistics, sociolinguistics, educational linguistics and linguistic anthropology. In other words, disciplines with a great variety of epistemological and methodological preferences.

The so-called 'hardcore positivists' created a sensation in applied linguistics around 2010 by siding with the postmodernists on some crucial epistemological and methodological points.

\section{The dynamic system theory attack on quantitative affective research}

The change came after Larsen-Freeman (1997) introduced chaos/complexity science in applied linguistics. She argued that interlanguages could be seen as complex, dynamic, non-linear systems. Crucially, she stated that 'progress in understanding SLA will not be made simply by identifying more and more variables that are thought to influence language learners' (1997: 156). She added that measurement of variables might in fact be useless in a dynamic system: 'If SLA is indeed a complex nonlinear process, we will never be able to identify, let alone measure, all of the factors accurately. And even if we could, we would still be unable to predict the outcome of their combination' (1997: 157).

These arguments won over a number of researchers at the heart of the positivist and 'modernist' paradigm and exerted a profound influence on the field. The first signs of a change of heart came in 2009 when Dörnyei claimed that dynamic system theory (DST) approaches often privilege a qualitative approach: 'SLA does not lend itself easily to quantitative investigations, because the number of confounding variables is extensive and some of them cannot be measured at the level of precision that is required' (Dörnyei 2009: 242). This view was not exactly new since the pioneers had admitted as much 17 years earlier: 'There are probably as many factors that might account for individual differences in achievement in a L2 as there are individuals. However, they may 
be grouped into one of the two classifications of cognitive or affective variables' (Gardner and MacIntyre 1992: 212). The authors thus agreed that every individual learner is unique but that learners still have common characteristics which allowed quantitative analysis at group level. Dörnyei and Ryan (2015: 102) describe the DST turn in motivation research as a liberation from 'a single governing orthodoxy' (read 'Gardner') following the earlier blow against Gardner's social psychological research, which was largely superseded by Dörnyei’s self-related research.

Dörnyei (2009) expressed doubts about the study of IDs because of their fuzziness and the assumption of stability, leading him to reject the 'ID myth'. Dörnyei (2012), influenced by DST, abandoned his previous tolerant view of both quantitative and qualitative research by stating: 'the central tendency observed in a group may not be true of any particular person in the participant sample. ... group averages ... iron out idiosyncratic details that are at the heart of understanding development in dynamic systems' (2012: 4). The rejection of group averages is couched is positive terms, namely 'an auspicious wave of methodological experimentation and innovation in the field' (Dörnyei and Ryan 2015: 102). This new view culminated in the book Motivational Dynamics in Language Learning (2015), edited by Dörnyei, MacIntyre and Henry. In its foreword, John Schumann, the respected veteran SLA researcher, made the following astonishing claim: 'The experimental method itself may be a manifestation of our tendency to isolate a single cause, to see averages as the truth [emphasis added], and to dismiss variation as noise. Complicating the matter, is the fact that the search for a single causal variable often works and has often been very informative; we have learned a lot from this way of thinking. ... DST challenges this approach to understanding complex phenomena' (2015: xviii). Schumann adds that 'the book challenges several assumptions about "scientific" research in SLA' (2015: Xv). One such assumption is that

truth is found in the study of inter-individual variability among large numbers of subjects. Another is that causal effects are either singular or few in number and that they operate linearly. An additional assumption is that categories and their labels refer to clearly identifiable entities in the world. The adoption of DST allows, indeed, compels us to eschew notions of single causes, linear causality, immutable categories, and highly specified endpoints.

(Schumann 2015: xv)

I am not dismissing some of the key points of DST, such as the observation that 'the manifold issues and factors affecting SLA are interrelated' (Dörnyei, Macintyre \& Henry 2015: 1), that change in SLA is non-linear and that it good to look at the whole system (a holistic view). I am only worried that the statement that that it is necessary to find 'alternatives to conventional quantitative research methodologies which, by and large, relied on statistical procedures 
to examine linear rather than dynamic relationships' (ibid.: 2) might be interpreted as an overall rejection of quantitative research methodologies. Looking for alternatives to existing methods is excellent, but it does not mean that quantitative research methodologies suddenly lose their usefulness or validity. Also, the fact that the process of SLA is linked to multiple linguistic, situational, psychological, political, sociological and educational factors does not mean that we should abandon the search for cause-effect relationships in SLA. These relationships can only be detected through quantitative analysis. Most ID researchers agree that any dependent variable is linked to many independent variables. The fact that it is statistically impossible to include all potential variables in a single research design should not become an argument to give up statistical analysis. It is my strong belief that judicious statistical analyses on sufficiently large data sets allow researchers to spot patterns in the data and that group averages remain meaningful.

I would counter the argument that statistical analysis erases the unique characteristics of individual learners by arguing that mixed-methods approaches allow the identification of general patterns at group level, which can be complemented by the analysis of individual cases (Creswell 2015; Schrauf 2016). If the quantitative analysis precedes the qualitative analysis, researchers can even pick participants depending on their position on some dimension of interest. Adopting mixed-methods approaches allows researchers to combine the best of both worlds: 'the combination of approaches capitalizes on the strengths and overcomes the weaknesses of either approach separately' (Schrauf 2016: 7). This was also the opinion of Dörnyei (2007: 30): 'it is my personal belief that mixing methods has great potential in most research contexts.'

Addressing the reader, Creswell (2015) explains: 'collecting and analyzing both quantitative .... and qualitative data ... adds value to a study and enables you to understand your problem and questions better than simply reporting survey results and interview results separately' (Creswell 2015: x). He does point out that mixed-methods require rigorous methodology for both the quantitative and qualitative components and a strong rationale for combining the both approaches (Creswell 2015: 4).

The quantitative part of a mixed-methods study ensures 'hypothesis-driven research with attention to independent and dependent variables; designs that include quasi-experiments and correlational studies; attention to closed-ended data collection instruments; and descriptive and inferential statistical analyses' (Schrauf 2016: 3). The phenomenon of non-linearity in SLA (such as U-shaped behaviour in interlanguage) is also well known and cannot be used as an argument to reject quantification.

The qualitative part in a mixed-methods design allows researchers to explore potential causes for some of the patterns that emerged in the quantitative analyses. By focusing on the experiences of participants, they can gain a better understanding of 'their perceptions, opinions, evaluations, emotional framings, expectations, and agenda relative to the topic of the study' (Schrauf 2016: 3). 
Schrauf (2016) points out that these qualitative data, just like the quantitative data, need to go through a process of analysis. The textual data need to be coded, which will be influenced by the researcher's methodological orientation, their disciplinary commitment, the participants themselves and the research topic itself (Schrauf 2016: 5). Qualitative research implies a practical trade-off between the sample size and the potential generalizability of the findings given how much effort is needed in collecting face-to-face data, transcribing the data and coding it. Researchers have to ask themselves whether they have captured the lived experience of their participants, and whether these findings can be generalised to a larger group (Schrauf 2016: 7).

The next point made by Schumann (in Dörnyei, Macintyre \& Henry 2015) was the criticism of the belief of traditional quantitative SLA researchers in 'simple' cause-effect relationships. Most quantitative researchers are aware that there is no such thing, and that correlation does not imply causation. In other words, anyone with a minimal knowledge in statistics knows that a positive correlation between two variables does not allow the researcher to determine the direction of the relationship, or the possibility that some other variable might be lurking in the background that might be responsible for the relationship. Causal pathways in SLA can and should be assumed to be multidirectional, such as the relationship between L2 proficiency and psychological and social factors, where L2 proficiency is both a cause and an effect (Schrauf 2013).

The next statement that I would like to discuss is Schumann's position on categories, namely the 'assumption that categories and their labels refer to clearly identifiable entities in the world' (Schumann 2015: xv). The scope of this statement far exceeds the remit of the present contribution. Suffice it to say that categories imply a certain level of abstraction, that the borders can be fuzzy and that individuals can straddle or move between different categories. In other words, the existence of categories does not exclude complexity nor hybridity, nor the creation of new blended categories. Nobody would object to the fact that categories can expand or contract, that people can move from one category to another or have one foot in different categories; it can relate to culinary preferences, religion, sports, sexual orientation, gender or culture, to name but a few. Unhappiness with categories does not imply that categorisation should be rejected all together. In Dewaele (2018b), I criticised the use of certain common categories in applied linguistic research, including that of 'native speakers' versus 'non-native speakers.' I have suggested that a more holistic and neutral categorisation is needed that recognises individuals as learners and legitimate users of many languages (cp. Cook 2002) and does not use terms that imply superiority or inferiority. In other words, the dichotomy between first language (L1) users versus foreign language (LX) users makes more sense to me, since it does not imply any level of proficiency and since multilinguals are by definition multicompetent users (Cook 2016) of both L1(s) and of LX(s).

The following point to address in the DST perspective is the status and the value of statistics. Dörnyei, Macintyre and Henry (2015) are realistic enough to 
agree that traditional quantitative methods cannot simply be discarded: 'Correlations, analyses of variance, interviews, classroom observation schemes and other methods will continue to have their place in the literature for the foreseeable future' (2015: 424). But they suggest that these methods are by nature focused on states rather than processes, which is the focus of DST research: 'Alongside these methods, filling in some of the blanks left by the focus on product, will be studies of dynamic processes. Each strand will inform the other' (2015: 424).

The suggestion that researchers ignored dynamic processes in SLA before the arrival of DST is plainly wrong. Dörnyei himself is the best example. He came up with the beautiful metaphor of tides to describe variation in motivation (Dörnyei 2001: 16): 'to account for the "daily ebb and flow" of motivation, we need to develop a motivation construct that has a prominent temporal dimension.' It is thus surprising that Dörnyei, MacIntyre and Henry (2015) claim that traditionally variation was treated as noise (2015: 424) and argue that not only will the DST perspective prioritise individual accounts over groups; it 'values variation as strongly as states' (ibid.). It is pretty obvious that variation had caught their attention since the start of their academic careers and that the tradition of looking at variation both in applied linguistic research went back to Labov's variational sociolinguistics in the 1960s, including those who looked at the acquisition of sociolinguistic competence in SLA (Dewaele 2002; Howard, Mougeon \& Dewaele 2012). In other words, the claim that researchers have only just started to value the dynamic nature of SLA is exaggerated.

To sum up, both poststructuralists and DST researchers, despite their different theoretical and epistemological origins, have developed very similar criticisms towards quantitative research into IDs research in the sociopsychological tradition (see Table 2).

\section{Defending mixed-methods approaches in applied linguistic research}

In defence of the quantitative approach in applied linguistic research and in SLA research in particular, I would argue that an exclusive focus on the microscopic individual level might hinder generalizability of findings outside the narrow field of enquiry. Van Geert, one of the leading figures in DST research, claims that 'individual case studies may not reveal much about the population of language learners, but they do have a direct bearing on theory' (van Geert 2011: 276). I would not deny that the study of individual cases can enlighten the theory, but there is a danger that the choice of specific cases might be influenced by researchers' (un)conscious bias, focusing narrowly on cases that can confirm the theory and excluding the ones that might disconfirm it. Dörnyei (2007) was very much aware of this danger and proposed to counter it with method and data triangulation: 
Table 2: Summary of the poststructuralist and DST positions in motivation research.

\begin{tabular}{|l|l|}
\hline Poststructuralist perspective & DST perspective \\
\hline Homogeneity is an illusion & Homogeneity is an illusion \\
\hline No clear causality & No clear causality \\
\hline No linear development & No linear development \\
\hline (Social) context is crucial & Infinitely rich complex system \\
\hline $\begin{array}{l}\text { Separation of independent variables is } \\
\text { artificial }\end{array}$ & $\begin{array}{l}\text { Separation of independent variables is } \\
\text { artificial }\end{array}$ \\
\hline $\begin{array}{l}\text { Traditional statistical methods are } \\
\text { reductionist }\end{array}$ & $\begin{array}{l}\text { Traditional statistical methods are } \\
\text { reductionist }\end{array}$ \\
\hline $\begin{array}{l}\text { In favour of longitudinal ethnographic } \\
\text { approach with rich and dense data of } \\
\text { individual cases }\end{array}$ & $\begin{array}{l}\text { In favour of longitudinal (qualitative) } \\
\text { approach, over different timescales, } \\
\text { case studies have appropriate level of } \\
\text { granularity (dense data) }\end{array}$ \\
\hline Against generalisation & Against generalisation \\
\hline
\end{tabular}

Triangulation has been traditionally seen as one of the most efficient ways of reducing the chance of systematic bias in a qualitative study because if we come to the same conclusion about a phenomenon using a different data collection/analysis methods or a different participant sample, the convergence offers strong validity evidence.

(Dörnyei 2007: 61).

On the point of triangulation, Dörnyei was in perfect agreement with Pavlenko (2008).

The debate on benefits of the microscopic, individual-level approach versus that of a group-level approach could be translated into a metaphor of trees and forests. I would argue that an exclusive focus on individual trees might harm a more holistic understanding of the forest. An individual tree might be exceptionally strong and tall or be stunted and suffer from some disease. Only by considering the whole forest can researchers determine the causes, depending on the type of tree, the location in the forest, the distance from a water source, the amount of light and the presence of specific types of beetles or fungi. To address the problem, a combination of tree-level and forest-level analyses are needed. An exclusive focus on either level is unlikely to lead to a deep understanding of the complexity of the system and, by implication, do the forest any good. This last point is important because the foresters' crucial responsibility is preserving and caring for the whole forest. If we now substitute trees by learners, forests by 
cohorts of learners and foresters by applied linguists, it becomes obvious that researchers have a responsibility that extends far beyond theoretical concerns they share with like-minded colleagues. Rather than retreating in their comfy, well-insulated tree huts, observing the growth of the bark of the tree with one eye tightly shut and then, after writing up their observations, claim that since the dynamic process of growth is so complex it is impossible to draw any general conclusion, applied linguists should be doing exactly that. They need to look for ways to understand SLA phenomena not just at an individual level but also at group level, testing methods to awaken learners' engagement, to heighten their enjoyment, to manage their anxiety and to stimulate their desire to acquire new skills, new knowledge and new identities in the L2. Through triangulation and mixed-methods designs, applied linguists can hope to gain a better understanding of the complex dynamic interlanguage and belief systems of their learners. These insights need to lead to some form of generalisation and recommendation that can inform authors of foreign language curricula and foreign language teacher trainers. My point is that applied linguists have a duty towards foreign language teachers around the world. Claiming that every learner is so unique that no generalisation is possible means effectively turning one's back on both learners and teachers and washing one's hands of the messy classroom reality.

Friendly epistemological and ontological debates are healthy in applied linguistics. The former focuses on types of evidence used to make claims, the latter on the question whether reality is multiple or singular (Creswell 2015). I have been arguing in favour of Creswell's view that 'reality is found in a theory that helps to explain behaviour among a large number of people' rather than the opposing view 'that reality is better determined by different individual perspectives than one general explanation' (Creswell 2015: 16).

The argument about quantitative methods being 'reductionist' might be partly true but it is insufficient to therefore categorically reject the use of quantitative methods. Indeed, no research design can include all independent variables that might potentially be linked to the dependent variables. Out of a potentially infinite number of variables, the researcher needs to select a finite number based on previous research in various disciplines, on conversations with learners and teachers and on the researchers' own intuitions. In experimental research, it is a matter of finding out whether the manipulation has had an effect on learners' performance, emotions, knowledge or attitudes. In more exploratory research, the aim is to establish networks of relationships between variables, and seeing how these may shift synchronically or diachronically. Large numbers of variables can be reduced. As Dörnyei (2007: 206) pointed out, 'Every initial quantitative dataset has many more variables than necessary.' Reducing the data involves both data manipulation and analysis and allows the researcher to 'create fewer but broader variables that carry almost as much information as the original variables' (ibid.). Data reduction involves a certain loss of information but it allows the researcher to carry out solid statistical 
analyses, complementary or parallel to qualitative analyses, and thus carry out vital triangulation.

\section{Conclusion}

I argue that quantitative and qualitative approaches are akin to the left and right eyes of researchers. Both approaches are perfectly legitimate and can function on their own. The growing popularity of poststructuralist and DST-inspired views is swinging the pendulum in the direction of qualitative approaches in applied linguistics. I express the hope here that the pendulum will not go too far. A combination of quantitative and qualitative approaches offers researchers the unsurpassed advantage of binocular vision, allowing them to perceive three-dimensional images of phenomena. For the field to progress researchers need to see more dimensions through different methods and epistemologies (Prior 2019). This view is expressed poetically by Pavlenko (2002): 'poststructuralist approaches will bloom best when surrounded by other flowers in the garden of theory and practice, giving rise to present and future debates and controversies' (Pavlenko 2002: 299) and it is shared by DST researchers, but their push for more emic, qualitative research may unwittingly push quantitative approaches in an underdog position. Finally, applied linguists have a major responsibility towards foreign language teachers and learners, which means their work should contain implications for the garden of theory and practice.

\section{Acknowledgement}

A previous version of this chapter was presented as a provocative closing plenary at the First Psychology of Language Learning Conference in 2014 at the university of Graz, in the presence of Zoltan Dörnyei, Peter MacIntyre and other dear colleagues. I would like to thank the conference participants for their feedback, as well as the reviewers and the editors of the present volume for their excellent suggestions and corrections.

\section{References}

Cook, V.J. (ed.) 2002 Portraits of the L2 User. Clevedon: Multilingual Matters. Cook, V.J. 2016 Premises of multi-competence. In Cook, V.J. and Li Wei (eds), The Cambridge handbook of linguistic multi-competence. Cambridge: Cambridge University Press. pp. 1-25.

Creswell, J.W. 2015 A concise introduction to mixed methods research. Thousand Oaks, CA: Sage Publications. 
Dewaele, J.-M. 2002 Variation, chaos et système en interlangue française. AILE, 17: 143-167.

Dewaele, J.-M. 2009a Individual differences in second language acquisition. In Ritchie, W.C. and Bhatia, T.K. (eds), The new handbook of second language acquisition. Bingley: Emerald. pp. 623-646.

Dewaele, J.-M. 2009b Perception, attitude and motivation. In Cook, V.J. and Li Wei (eds), Language teaching and learning. London: Continuum. pp. 163-192.

Dewaele, J.-M. 2012 Personality traits as independent and dependent variables. In Mercer, S., Ryan, S. and Williams, M. (eds), Psychology for language learning: Insights from research, theory and practice. Basingstoke: Palgrave Macmillan. pp. 42-58.

Dewaele, J.-M. 2013 Emotions in multiple languages. 2nd ed. Basingstoke: Palgrave Macmillan.

Dewaele, J.-M. 2018a Special issue 'Emotions in SLA'. Studies in Second Language Learning and Teaching, 8(1). DOI: https://doi.org/10.14746/ ssllt.2018.8.1.1.

Dewaele, J.-M. 2018b Why the dichotomy 'L1 versus LX user' is better than 'native versus non-native speaker'. Applied Linguistics, 39(2): 236-240. DOI: https://doi.org/10.1093/applin/amw055

Dewaele, J.-M. and MacIntyre, P.D. 2014 The two faces of Janus? Anxiety and enjoyment in the foreign language classroom. Studies in Second Language Learning and Teaching, 4(2): 237-274. DOI: https://doi.org/10.14746/ ssllt.2014.4.2.5

Dörnyei, Z. 2001 Motivational strategies in the language classroom. Cambridge: Cambridge University Press.

Dörnyei, Z. 2005 The psychology of the language learner: Individual differences in Second Language Acquisition. Mahwah, NJ: Lawrence Erlbaum Associates.

Dörnyei, Z. 2007 Research methods in applied linguistics. Oxford: Oxford University Press.

Dörnyei, Z. 2009 The psychology of second language acquisition. Oxford: Oxford University Press.

Dörnyei, Z. 2012 Motivation in language learning. Shanghai: Shanghai Foreign Language Education Press.

Dörnyei, Z., MacIntyre, P.D. and Henry, A. (eds) 2015 Motivational dynamics in language learning. Bristol: Multilingual Matters.

Dörnyei. Z. and Ryan, S. 2015 The psychology of the language learner revisited. New York: Routledge.

Farhady, H. 2013 Quantitative methods. In Chapelle, C.A. (ed.), The encyclopedia of applied linguistics. Oxford: Blackwell. DOI: https://doi. org/10.1002/9781405198431.wbeal0989

Firth, A. and Wagner, J. 2007 On discourse, communication, and (some) fundamental concepts in SLA research. The Modern Language Journal, 91: 757772. DOI: https://doi.org/10.1111/j.1540-4781.2007.00667.x 
Gardner, R.C. and MacIntyre, P.D. 1992 A student's contribution to second language learning: Part I, cognitive factors. Language Teaching, 25: 211-220. DOI: https://doi.org/10.1017/S026144480000700X

Gardner, R.C. and MacIntyre, P.D. 1993 On the measurement of affective variables in second language learning. Language Learning, 43(2): 157-194. DOI: https://doi.org/10.1111/j.1467-1770.1992.tb00714.x

Howard, M., Mougeon, R. and Dewaele, J.-M. 2013 Sociolinguistics and second language acquisition. In Bayley, R., Cameron, R. and Lucas, C. (eds), The Oxford handbook of sociolinguistics. New York: Oxford University Press. pp. 340-359. DOI: https://doi.org/10.1093/oxfordhb/9780199744084.013.0041

Kramsch, C. 2014 Language and culture. AILA Review, 27(1): 30-55. DOI: https://doi.org/10.1075/aila.27.02kra

Kramsch, C. 2006 Desire in language: The neglected dimension of language learning. In Duxa, S., Hu, A. and Schmenk, B. (eds), Grenzen überschreiten. Menschen, Sprachen, Kulturen. Festschrift für Inge Christine Schwerdtfeger zum 60. Geburtstag. Tübingen: Gunter Narr. pp. 209-224.

Lantolf, J. and Pavlenko, A. 2001 (S)econd (L)anguage (A)ctivity theory: Understanding second language learners as people. In Breen, M. (ed.), Learner contributions to language learning: New directions in research. London: Longman. pp. 141-158.

Larsen-Freeman, D. 1997 Chaos/complexity science and second language acquisition. Applied Linguistics, 18(2): 141-165. DOI: https://doi.org/10.1093/ applin/18.2.141

Larsen-Freeman, D. and Long, M. 1991 An introduction to second language acquisition research. London: Longman.

MacIntyre, P.D. 2007 Willingness to communicate in the second language: Understanding the decision to speak as a volitional process. The Modern Language Journal, 91: 564-576. DOI: https://doi.org/10.1111/j.1540-4781.2007.00623.x

MacIntyre, P.D., Gregersen, T. and S. Mercer. (eds) 2016 Positive psychology in SLA. Bristol: Multilingual Matters.

Markee, N. 2013 Emic and etic in qualitative research. In Chapelle, C. (ed.), The encyclopedia of applied linguistics. Oxford: Blackwell. DOI: https://doi. org/10.1002/9781405198431.wbeal0366

Norton Peirce, B. 1995 Social identity, investment, and language learning. TESOL Quarterly, 29: 9-31. DOI: https://doi.org/10.2307/3587803

Pavlenko, A. 2002 Poststructuralist approaches to the study of social factors in second language learning and use. In Cook, V.J. (ed.), Portraits of the L2 user, Clevedon: Multilingual Matters. pp. 277-302.

Pavlenko, A. 2008 Narrative analysis in the study of bi- and multilingualism. In Moyer, M. and Li Wei (eds), The Blackwell guide to research methods in bilingualism. Oxford: Blackwell. pp. 311-325. DOI: https://doi. org/10.1002/9781444301120.ch18

Pavlenko, A. 2013 The affective turn in SLA: From 'affective factors' to 'language desire' and 'commodification of affect'. In Gabrys-Barker, D. and Bielska, J. 
(eds), The affective dimension in second language acquisition. Bristol: Multilingual Matters. pp. 3-28.

Pike, K.L. 1954 Language in relation to a unified theory of the structure of human behaviour. The Hague: Mouton.

Pomerantz, A. 2013 Narrative approaches to second language acquisition. In Chapelle, C.A. (ed.), The encyclopedia of applied linguistics. Oxford: Blackwell. DOI: https://doi.org/10.1002/9781405198431.wbeal0849

Prior, M.T. 2019 Elephants in the room: An 'affective turn', or just feeling our way? The Modern Language Journal, 103(2): 516-527. DOI: https://doi. org/10.1111/modl.12573

Saito, K., Dewaele, J.-M. and Hanzawa, K. 2017 A longitudinal investigation of the relationship between motivation and late second language speech learning in classroom settings. Language and Speech, 60(4): 614-632. DOI: https://doi.org/10.1177/0023830916687793

Schrauf, R. 2013 Using correspondence analysis to model immigrant multilingualism over time. In Duarte, J. and Gogolin, I. (eds), Linguistic superdiversity in urban areas - research approaches. Amsterdam: John Benjamins. pp. 27-44. DOI: https://doi.org/10.1075/hsld.2.04sch

Schrauf, R. 2016 Mixed methods: Interviews, surveys, and cross-cultural comparisons. Cambridge: Cambridge University Press. DOI: https://doi. org/10.1017/9781316544914

Ushioda, E. 2001 Language learning at university: Exploring the role of motivational thinking. In Dörnyei, Z. and Schmidt, R. (eds), Motivation and Second Language Acquisition. Honolulu, HI: University of Hawai'i Press. pp. 91-124.

van Geert, P. 2011 The contribution of complex dynamic systems to development. Child Development Perspectives, 5: 273-278. DOI: https:/doi.org/ 10.1111/j.1750-8606.2011.00197.x 